\title{
Rethinking the role of L-type voltage-gated calcium channels in fear memory extinction
}

\author{
Glenn E. Schafe ${ }^{1}$ \\ Department of Psychology and Interdepartmental Neuroscience Program, Yale University, New Haven, Connecticut 06520, USA
}

The neurobiological mechanisms underlying extinction of fear memories have attracted considerable experimental interest in recent years, due in part to the clinical implications of this line of research for the treatment of fear-based psychiatric disorders (Milad et al. 2006; Sotres-Bayon et al. 2006). Several years ago, it was discovered that antagonists of the L-type voltage-gated calcium channel (L-VGCC) impair both extinction learning and longterm recall of fear extinction. In those studies, mice given systemic administration of either of the dihydropyridine (DHP) compounds nifedipine or nimodipine were observed to exhibit impairments in fear extinction, as measured by "freezing" behavior, both within a session and also when tested $\sim 24 \mathrm{~h}$ later (Cain et al. 2002, 2005; Suzuki et al. 2004). This finding was of interest given the well-established role of L-VGCCs in synaptic plasticity (Grover and Teyler 1990), in which signaling via the L-VGCC is thought to link activity at the membrane with transcriptional events in the nucleus (Dolmetsch et al. 2001). Further, L-VGCCs are known to play an essential role in synaptic plasticity in the amygdala (Weisskopf et al. 1999; Bauer et al. 2002), suggesting that signaling via L-VGCCs might be a mechanism by which long-term extinction memories are formed and stored. While an initially attractive hypothesis, three new articles appearing in this issue of Learning \& Memory force us to re-examine that view.

McKinney et al. (2008, this issue) use a genetic and pharmacological approach to examine the role of different L-VGCC isoforms in extinction of context fear memory. L-VGCCs consist of a variety of subunits, of which $\mathrm{Ca}_{\mathrm{v}} 1.2$ and $\mathrm{Ca}_{\mathrm{v}} 1.3$ are the major isoforms expressed in the brain (Striessnig et al. 2006). In a previous study, McKinney and Murphy showed that forebrain deletion of the $\mathrm{Ca}_{\mathrm{v}} 1.3$ isoform impairs consolidation of context fear memory; that is, fear acquisition and short-term memory (STM) are intact, while long-term memory (LTM) is impaired (McKinney and Murphy 2006). However, in that study, deletion of $\mathrm{Ca}_{\mathrm{v}} 1.3$ had no effect on fear extinction; $\mathrm{Ca}_{\mathrm{v}} 1.3$ knockout mice show normal within-session extinction and intact long-term recall of extinction $24 \mathrm{~h}$ later (McKinney and Murphy 2006). In the present article, McKinney et al. (2008) examine the role of $\mathrm{Ca}_{\mathrm{v}} 1.2$ in fear memory extinction. A recent study found that deletion of $\mathrm{Ca}_{\mathrm{v}} 1.2$ impairs spatial learning and the L-VGCC-dependent form of LTP in the hippocampus (Moosmang et al. 2005). Surprisingly, however, McKinney et al. (2008) find that mice lacking $\mathrm{Ca}_{\mathrm{v}} 1.2$ in the forebrain have intact acquisition, consolidation, and extinction of fear memory. Thus, using a genetic approach, forebrainexpressed $\mathrm{Ca}_{\mathrm{v}} 1.3$ appears necessary for fear memory consolidation, but neither $\mathrm{Ca}_{\mathrm{v}} 1.3$ nor $\mathrm{Ca}_{\mathrm{v}} 1.2$ appears to be necessary, at least in isolation, for fear memory extinction.

Turning to a pharmacological analysis, McKinney et al. (2008) next revisit the question of whether L-VGCC antagonists impair fear extinction, and, if so, why this method of manipulating L-VGCCs is so much more effective than using a molecular genetic approach. They first verify that systemic administration of a dose of nifedipine that has been used in previous experi-

'Corresponding author.

E-mail glenn.schafe@yale.edu; fax (203) 432-7172.

Article is online at http://www.learnmem.org/cgi/doi/10.1101//m.996908. ments (Cain et al. 2002, 2005) impairs fear extinction. In their hands, mice treated with nifedipine exhibit impaired withinsession extinction relative to vehicle-injected mice and impaired extinction recall $\sim 24 \mathrm{~h}$ later. Remarkably, however, this same dose of nifedipine is observed to impair locomotor activity in an open field test and to exhibit aversive properties in its own right. That is, pairing of nifedipine alone with a novel context appears sufficient to condition a long-lasting fear-like response to that context and in a context-specific manner. Effectively, extinction training under the influence of nifedipine appears to amount to retraining using a different US. Thus, the authors suggest, the within-session impairment of fear extinction following systemic injections of L-VGCC antagonists is likely the result of acute toxicity masking as freezing behavior, rapid re-acquisition of fear to the context in which the animal is being extinguished, or both factors. Similarly, impaired long-term "extinction recall" (at 24 h) is likely due, in part, to long-term recall of fear that has been re-acquired as a consequence of pairing the extinction context with systemic L-VGCC blockade.

The findings of Busquet et al. (2008, this issue) cast further doubt on the role of L-VGCCs in fear memory extinction. In agreement with previous findings (Cain et al. 2002, 2005; Suzuki et al. 2004), they first show that systemic administration of nifedipine impairs fear extinction learning to both contextual and auditory cues; mice receiving vehicle injections show a characteristic extinction curve, while those receiving nifedipine continue to exhibit "freezing" behavior throughout the extinction session. Using a novel mouse model expressing DHP-insensitive $\mathrm{Ca}_{\mathrm{v}} 1.2$ L-VGCCs, they next show that this effect is completely blocked in $\mathrm{Ca}_{\mathrm{v}} 1.2 \mathrm{DHP}^{-/-}$mice, suggesting that the effect of systemically administered nifedipine on fear extinction is mediated through $\mathrm{Ca}_{\mathrm{v}} 1.2$ rather than $\mathrm{Ca}_{\mathrm{v}} 1.3$. Remarkably, however, Busquet et al. (2008) fail to find an effect of multiple doses of nifedipine on fear extinction following intracerebroventricular infusion of the drug, suggesting that the effects of nifedipine on fear extinction are mediated via peripheral $\mathrm{Ca}_{\mathrm{v}} 1.2$ channels. Further, in a test of activity in the open field, they show that mice given systemic injection of nifedipine exhibit marked reductions in exploratory behavior, possibly indicative of a hypotensive effect. This latter finding is consistent with the peripheral distribution of $\mathrm{Ca}_{\mathrm{v}} 1.2$ channels and the documented actions of L-VGCCs on peripheral vasodilation and hypotension (Kubo et al. 1981; Barrett et al. 1988).

At first glance, it might appear counterintuitive that a peripherally acting drug can influence the formation of an extinction memory if not by acting in the brain. The report by Waltereit et al. (2008, this issue), however, suggests a mechanism by which L-VGCC antagonists may act peripherally to influence fear memory extinction. In their experiments, Waltereit et al. systematically vary the timing of systemic injections of nifedipine relative to the onset of extinction training. They find that i.p. or s.c. injections of nifedipine are highly effective at impairing extinction of either context or auditory fear memories when given as many as 2 or $4 \mathrm{~h}$ prior to extinction training, respectively. Remarkably, however, the authors show that nifedipine peaks in blood serum as quickly as $30 \mathrm{~min}$ after administration and is nearly undetectable by $2 \mathrm{~h}$ following i.p. injection and by $4 \mathrm{~h}$ following 
s.c. injection. As a consequence, it is highly unlikely that blockade of L-VGCCs in the brain is responsible for the effects of nifedipine on fear extinction when administered at these intervals. Next, Waltereit et al. (2008) examine locomotor activity and rearing behavior in mice injected with nifedipine. In agreement with the findings of McKinney et al. (2008) and Busquet et al. (2008), they observe decreases in locomotor activity and a complete loss of rearing behavior that lasts up to $4 \mathrm{~h}$ after s.c. administration of nifedipine. Further, both i.p. and s.c. injections of nifedipine are associated with significant elevations in plasma corticosterone at either 2 or $4 \mathrm{~h}$ following injection, respectively. Thus, the authors suggest, nifedipine appears to induce a protracted stress response following systemic administration, which likely accounts for its observed effects on fear extinction. Interestingly, both acute and chronic stress have recently been shown to impair fear extinction (Izquierdo et al. 2006; Miracle et al. 2006), while leaving fear acquisition intact.

The findings of these three new articles clearly raise serious doubts about the role of L-VGCCs in fear memory extinction. Genetic deletion of either $\mathrm{Ca}_{\mathrm{v}} 1.2$ or $\mathrm{Ca}_{\mathrm{v}} 1.3$ in the forebrain appears to have no effect on fear extinction. And while systemically administered L-VGCC antagonists are clearly effective at impairing extinction memory, they appear to do so by producing undesirable secondary effects. There are multiple questions, however, left unanswered. Since $\mathrm{Ca}_{\mathrm{v}} 1.2$ and $\mathrm{Ca}_{\mathrm{v}} 1.3$ are knocked down in isolation in the McKinney et al. (2008) studies, might there be some kind of functional compensation? If so, it would appear to be unique to fear memory extinction given that $\mathrm{Ca}_{\mathrm{v}} 1.3$ knockout mice have impaired fear memory consolidation (McKinney and Murphy 2006). Further, given that deletion of $\mathrm{Ca}_{\mathrm{v}} 1.2$ and $\mathrm{Ca}_{\mathrm{v}} 1.3$ is confined to CaMKII-expressing excitatory neurons, are we missing a possible role for L-VGCCs in inhibitory networks during fear extinction? This is possible, but the pharmacological findings of Busquet et al. (2008) now suggest that a central role for L-VGCCs is unlikely. Another outstanding question concerns the effects of L-VGCC manipulations on fear memory consolidation. In a previous study, McKinney and Murphy (2006) found that forebrain deletion of $\mathrm{Ca}_{\mathrm{v}} 1.3$ impairs consolidation of context fear memory; acquisition and STM are intact, while LTM is impaired. These findings are consistent with those of Bauer et al. (2002), who found a similar effect on consolidation of an auditory fear memory following intra-amygdala infusion of the L-VGCC antagonist verapamil. However, most studies, including two published in this issue, have failed to find effects of L-VGCC blockade on memory consolidation (Cain et al. 2002; Suzuki et al. 2004). While McKinney et al. (2008) have suggested that this discrepancy may be due, in part, to differences in training protocol (McKinney and Murphy 2006), it is of interest to note that every study that has failed to find an effect of L-VGCC blockade on fear memory consolidation has employed systemic injection of an L-VGCC antagonist (Cain et al. 2002; Suzuki et al. 2004). Accordingly, the new findings presented in this issue might suggest that systemic administration of L-VGCC antagonists may be masking an effect on fear memory consolidation. Interestingly, while stress has been shown to impair fear extinction (Izquierdo et al. 2006; Miracle et al. 2006), it has been shown under certain circumstances to have the opposite effect on fear acquisition (Conrad et al. 1999). As a result, the negative findings obtained with systemic administration of LVGCC antagonists should be interpreted with caution.

In summary, the findings of the three new studies appearing in this issue collectively suggest that we should reconsider the role of L-VGCCs in fear memory extinction. They also emphasize the importance of carefully and systematically ruling out nonspecific effects of drugs on learning and memory processes, especially when systemic administration of a drug is used. These studies do not, however, suggest that pharmacological approaches are inferior to molecular genetic approaches. Each approach clearly has its advantages, and the use of each approach will continue to be instrumental in defining the cellular and molecular mechanisms underlying fear memory acquisition, consolidation, and extinction.

\section{References}

Barrett, R.J., Wright, K.F., Taylor, D.R., and Proakis, A.G. 1988. Cardiovascular and renal actions of calcium channel blocker chemical subgroups: A search for renal specificity. J. Pharm. Pharmacol. 40: 408-414.

Bauer, E.P., Schafe, G.E., and LeDoux, J.E. 2002. NMDA receptors and L-type voltage-gated calcium channels contribute to long-term potentiation and different components of fear memory formation in the lateral amygdala. J. Neurosci. 22: 5239-5249.

Busquet, P., Hetzenauer, A., Sinnegger-Brauns, M.J., Striessnig, J., and Singewald, N. 2008. Role of L-type Ca channel isoforms in the extinction of conditioned fear. Learn. Mem. (this issue), doi: 10.1101/lm.886208.

Cain, C.K., Blouin, A.M., and Barad, M. 2002. L-type voltage-gated calcium channels are required for extinction, but not for acquisition or expression, of conditional fear in mice. J. Neurosci. 22: $9113-9121$.

Cain, C.K., Godsil, B.P., Jami, S., and Barad, M. 2005. The L-type calcium channel blocker nifedipine impairs extinction, but not reduced contingency effects, in mice. Learn. Mem. 12: 277-284.

Conrad, C.D., LeDoux, J.E., Magarinos, A.M., and McEwen, B.S. 1999. Repeated restraint stress facilitates fear conditioning independently of causing hippocampal CA3 dendritic atrophy. Behav. Neurosci. 113: $902-913$.

Dolmetsch, R.E., Pajvani, U., Fife, K., Spotts, J.M., and Greenberg, M.E. 2001. Signaling to the nucleus by an L-type calcium channel-calmodulin complex through the MAP kinase pathway. Science 294: 333-339.

Grover, L.M. and Teyler, T.J. 1990. Two components of long-term potentiation induced by different patterns of afferent activation. Nature 347: 477-479.

Izquierdo, A., Wellman, C.L., and Holmes, A. 2006. Brief uncontrollable stress causes dendritic retraction in infralimbic cortex and resistance to fear extinction in mice. J. Neurosci. 26: 5733-5738.

Kubo, T., Fujie, K., Yamashita, M., and Misu, Y. 1981. Antihypertensive effects of nifedipine on conscious normotensive and hypertensive rats. J. Pharmacobiodyn. 4: 294-300.

McKinney, B.C. and Murphy, G.G. 2006. The L-type voltage-gated calcium channel $\mathrm{Ca}_{\mathrm{v}} 1.3$ mediates consolidation, but not extinction, of contextually conditioned fear in mice. Learn. Mem. 13: 584-589.

McKinney, B.C., Sze, W., White, J.A., and Murphy, G.G. 2008. L-type voltage gated calcium channels in conditioned fear: A genetic and pharmacological analysis. Learn. Mem. (this issue). doi: 10.1101/lm.893808.

Milad, M.R., Rauch, S.L., Pitman, R.K., and Quirk, G.J. 2006. Fear extinction in rats: Implications for human brain imaging and anxiety disorders. Biol. Psychol. 73: 61-71.

Miracle, A.D., Brace, M.F., Huyck, K.D., Singler, S.A., and Wellman, C.L. 2006. Chronic stress impairs recall of extinction of conditioned fear. Neurobiol. Learn. Mem. 85: 213-218.

Moosmang, S., Haider, N., Klugbauer, N., Adelsberger, H., Langwieser, N., Muller, J., Stiess, M., Marais, E., Schulla, V., Lacinova, L., et al. 2005. Role of hippocampal $\mathrm{Ca}_{\mathrm{v}} 1.2 \mathrm{Ca}^{2+}$ channels in NMDA receptor-independent synaptic plasticity and spatial memory. $J$. Neurosci. 25: 9883-9892.

Sotres-Bayon, F., Cain, C.K., and LeDoux, J.E. 2006. Brain mechanisms of fear extinction: Historical perspectives on the contribution of prefrontal cortex. Biol. Psychiatry 60: 329-336.

Striessnig, J., Koschak, A., Sinnegger-Brauns, M.J., Hetzenauer, A., Nguyen, N.K., Busquet, P., Pelster, G., and Singewald, N. 2006. Role of voltage-gated L-type $\mathrm{Ca}^{2+}$ channel isoforms for brain function. Biochem. Soc. Trans. 34: 903-909.

Suzuki, A., Josselyn, S.A., Frankland, P.W., Masushige, S., Silva, A.J., and Kida, S. 2004. Memory reconsolidation and extinction have distinct temporal and biochemical signatures. J. Neurosci. 24: 4787-4795.

Waltereit, R., Mannhardt, S., Nescholta, S., Maser-Gluth, C., and Bartsch, D. 2008. Selective and protracted effect of nifedipine on fear memory extinction correlates with induced stress response. Learn. Mem. (this issue), doi: 10.1101/lm.808608.

Weisskopf, M.G., Bauer, E.P., and LeDoux, J.E. 1999. L-type voltage-gated calcium channels mediate NMDA-independent associative long-term potentiation at thalamic input synapses to the amygdala. J. Neurosci. 19: 10512-10519. 


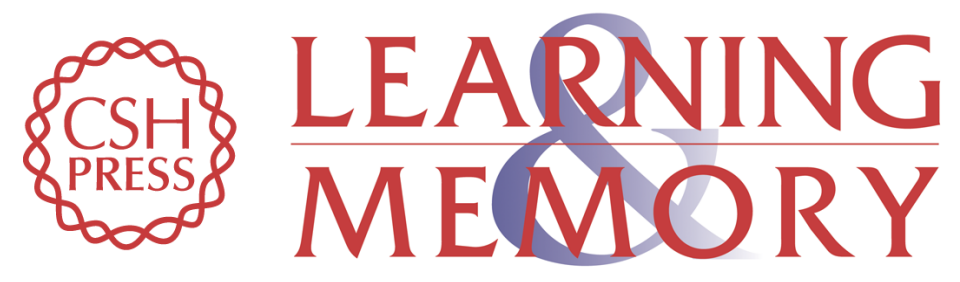

\section{Rethinking the role of L-type voltage-gated calcium channels in fear memory extinction}

Glenn E. Schafe

Learn. Mem. 2008, 15:

Access the most recent version at doi:10.1101//m.996908

References This article cites 20 articles, 12 of which can be accessed free at:

http://learnmem.cshlp.org/content/15/5/324.full.htmI\#ref-list-1

License

Email Alerting Receive free email alerts when new articles cite this article - sign up in the box at the Service top right corner of the article or click here. 